\title{
Self-criticism, intensity of perceived negative life events, and distress: Results from a two-wave study
}

\author{
Rui C. Campos ${ }^{\mathrm{a}, *, 1}$, Ronald R. Holden ${ }^{\mathrm{b}, 2}$, Berta Caçador ${ }^{\mathrm{a}}$, Ana Sofia Fragata ${ }^{\mathrm{a}}$, Cristina Baleizão $^{\mathrm{a}, 3}$ \\ ${ }^{a}$ University of Évora, Portugal \\ ${ }^{\mathrm{b}}$ Queen's University, Canada
}

\section{A R T I C L E I N F O}

\section{Keywords:}

Self-criticism

Negative life events

Distress

Two-wave study

Interaction

\begin{abstract}
A B S T R A C T
The aim of the present study was to evaluate whether changes in the maladaptive personality trait of selfcriticism and changes in the interaction between this trait and the intensity of perceived negative life events predict changes in distress over a period of five months. A final sample of 207 young adults participated, responding to the Depressive Experiences Questionnaire, the Life Experiences Survey, and the Brief Symptom Inventory. Results demonstrated that changes in self-criticism predicted changes in distress over and beyond the prediction associated with assessing the intensity of perceived negative life events. Further, changes in selfcriticism and perceived negative life events interacted in the prediction of changes in distress. Findings are discussed in terms of personality characteristics of self-critical individuals and of the construct of resilience.
\end{abstract}

Dysfunctional personality traits may confer a vulnerability to psychopathology (e.g., Kopala-Sibley \& Zuroff, 2014; Liu \& Alloy, 2010). For example, several studies have demonstrated that there is a relationship between the dysfunctional personality trait of self-criticism proposed by Blatt $(2004,2008)$ and depression (e.g., Kopala-Sibley, Zuroff, Hermanto, \& Joyal-Desmarais, 2016; Luyten et al., 2007; Sobrinho, Campos, \& Holden, 2016) or, more generally, with distress and other forms of psychopathology (Blatt, 2008; Kopala-Sibley, Zuroff, Russell, \& Moskowitz, 2014). Of note, self-criticism may be linked not only to depression but also to a wide range of psychopathologies (Blatt, 2008) such as bipolar disorder (Rosenfarb, Becker, Khan, \& Mintz, 1998), social anxiety (Kopala-Sibley et al., 2014), and borderline personality disorder (Levy, Edell, \& McGlashan, 2007). Self-criticism, labelled by some personality researchers as self-critical perfectionism, combines characteristics of having high personal standards with high levels of self-criticism. Self-critical individuals are also prone to feelings of unworthiness, indignity, failure, and guilt and they tend to engage in harsh self-scrutiny (Blatt, 1995).

Perceived negative life events have long been systematically related to distress (e.g., Beck, Rush, Shaw, \& Emery, 1979), and personality variables have been proposed as interacting with negative life events in predicting depression and distress (Blatt, 2004, 2008). Negative life events may be considered to be a proximal cause of psychopathology, in general, and of depression, in particular. According to Blatt (2004), current depression results from the interaction between internal factors - vulnerability factors - and external factors - such as negative life events. However, self-criticism may not only be a moderating agent but can also be a proactive factor that, itself, generates negative life experiences (Shahar, Joiner, Zuroff, \& Blatt, 2004). The explanatory value of negative life events in the aetiology of depression depends on the stress that is experienced by the individual because stress can have an activating effect for a pre-existing vulnerability (e.g., Mann, Waternaux, Haas, \& Malone, 1999).

Life events do not lead to an emotional perturbation on their own; what causes this disruption is how these events are interpreted by the individual (Lazarus \& Folkman, 1984; Sarason, Johnson, \& Siegel, 1978). As such, different individuals can experience the same events but react in quite distinct manners. For some, these life events may constitute a risk factor and, for others, these events may not have any significant impact on psychological functioning (Lazarus \& Folkman, 1984; Sarason et al., 1978). The perception that individuals have of their life experiences is a critical determining factor. However, the more negatively significant, intense, and unexpected these life events are, the greater the degree of distress that may be potentially experienced (e.g., Marshal, 2003).

Dysfunctional personality traits such as self-criticism, because it

\footnotetext{
* Corresponding author at: Departamento de Psicologia, Universidade de Évora, Apartado 94, 7002-554 Évora, Portugal.

E-mail address: rcampos@uevora.pt (R.C. Campos).

${ }^{1}$ Departamento de Psicologia, Escola de Ciências Sociais e Centro de Investigação em Educação e Psicologia (CIEP-UE), Universidade de Évora, Évora, Portugal.

${ }^{2}$ Department of Psychology, Queen's University, Kingston, Ontario, Canada.

${ }^{3}$ Departamento de Psicologia, Escola de Ciências Sociais, Universidade de Évora, Évora, Portugal.
} 